\title{
CHUVAS NO RIO GRANDE DO SUL: UM ESTUDO SOBRE AS PRECIPITAÇÕES ACUMULADAS INTENSAS NO ALTO URUGUAI GAÚCHO.
}

\author{
SANCHES, Fabio de Oliveira - fsanches.73@gmail.com \\ Universidade Federal da Fronteira Sul \\ BALEN, Darline Simoni - darlinebalen1@gmail.com \\ Universidade Federal da Fronteira Sul \\ SILVA, Roberto Valmir da - roberto.dasilva@gmail.com \\ Universidade Federal da Fronteira Sul \\ ROSA, Katia Kellem da - katiakellem@gmail.com \\ Universidade Federal do Rio Grande do Sul \\ RADÜNZ, André - alradunz@gmail.com \\ Universidade Federal da Fronteira Sul
}

\begin{abstract}
RESUMO: No mês de junho de 2014, a sequência de oito dias de chuvas ininterruptas promoveu uma série de transtornos (inundações, deslizamentos de terra, interdição de estradas) à parte da população dos estados do Rio Grande do Sul, Santa Catarina e Paraná. O trabalho objetiva identificar a ocorrência de eventos acumulados intensos de precipitação na região do alto Uruguai gaúcho, bem como seus mecanismos sinóticos responsáveis por esses acumulados de chuva. Dados diários de precipitação foram acumulados em grupos de cinco dias (pêntadas), perfazendo o total de 73 pêntadas anuais, no decorrer dos 53 anos da série (1961-2014). A aplicação do percentil 99 ao conjunto de dados determinou o valor do acumulado intenso $(157,4 \mathrm{~mm})$. Com base nesse valor foram calculadas a Frequência Absoluta, Frequência Relativa e o Tempo de Retorno desses acumulados intensos. Os resultados demonstraram que, dos dez eventos acumulados mais intensos, $70 \%$ ocorreram entre as pêntadas 30 e 47. Os eventos dos anos de 2014 e 1992 foram os mais intensos, acumulando, respectivamente, $366,7 \mathrm{~mm}$ e $328,0 \mathrm{~mm}$. Os resultados demonstraram que os acumulados pluviométricos intensos entre 200 e $250 \mathrm{~mm}$ possuem um tempo de retorno de cerca de cinco anos.Já a análise sinótica desses eventos revelou que tais eventos são consequência da formação de frentes estacionárias e semiestacionárias com duração mínima de 36 horas. Nos eventos de maior intensidade, o tempo de permanência do sistema frontal e estacionário foi de 120 horas, para 2014 e, 32 horas para 1992. Dessa forma, verifica-se que eventos acumulados intensos têm sido frequentes no decorrer dos 53 anos da série, podendo, estes, estarem relacionados às mudanças climáticas, sobretudo pela intensificação dos casos nos últimos anos (1992 e 2014).
\end{abstract}

Palavras-chave: pêntadas, eventos intensos, testes estatísticos, cartas sinóticas.

RAINS IN RIO GRANDE DO SUL: A STUDY OF INTENSE RAINFALL ACCUMULATED IN THE UPPER URUGUAY GAUCHO.

ABSTRACT: During June of 2014, eight days of continuous rainfall promoted a number of disorders (floods, landslides, road interdiction) to the population of the states of Rio Grande do Sul, Santa Catarina and Paraná. This study aims to identify the occurrence of accumulated intense precipitation events in the upper Uruguay Gaucho region as well as its synoptic mechanisms responsible for these accumulated rain. Daily precipitation data was accumulated in groups of five days (pentads), totaling 73 pentads per year, over the 53 years of the series (1961 - 2014). The value of accumulated intense rainfall $(157.4 \mathrm{~mm})$ was determined by applying the 99th percentile in the dataset. Based on this value, the time of return and the absolute and relative frequencies were calculated. The results showed that $70 \%$ of the ten most intense events occurred between 30th and 47th pentads. The events during the years of 2014 and 1992 were the most intense, respectively accumulating $366.7 \mathrm{~mm}$ and $328.0 \mathrm{~mm}$. The 
results showed that intense daily rainfall between $200 \mathrm{~mm}$ and $250 \mathrm{~mm}$ occurs once every five years. On the other hand, a synoptic analysis of these events showed they are a consequence of the formation of stationary fronts and semi stationary fronts that last at least 36 hours. In the event of greater intensity, the front stationary system lasted 120 hours for 2014 and 32 hours for 1992. In this way, it appears that these intense events have been frequent during of the 53 years of the series and it is possible that they are related to climate change, especially considering the increase of cases in recent years (1992 - 2014).

KEYWORDS: pentads, intense events, statistical test, synoptic maps.

\section{INTRODUÇÃO}

No mês de junho de 2014, a região do alto Uruguai gaúcho assistiu o acumulado mensal de 503,6 mm onde, normalmente, a climatologia das chuvas atinge $135 \mathrm{~mm}$. A maior parte desse acumulado mensal $(414,7 \mathrm{~mm})$ ocorreu entre os dias 23 e 30 de junho (oito dias).

As consequências desse elevado valor pluviométrico, sobretudo no decorrer desses oito dias, manifestaram-se por meio de uma série de problemas, gerando transtornos para as comunidades regionais, bem como para a região sul do país.

As Rodovias federais e estaduais foram interditadas devido ao surgimento de diversos pontos de movimentação de massa (queda de barreira) e de subsidência dos terrenos, que levaram ao aparecimento de rachaduras e feições erosivas nas pistas, graças a ação do escoamento superficial concentrado. Áreas ribeirinhas, igualmente, foram inundadas pela elevação do nível dos rios e córregos desabrigando um enorme contingente populacional.

Com o aumento da vazão nos principais rios da região, os vertedouros das UHE de Itá e UHE de Foz do Chapecó, ambas localizadas entre os estados do Rio Grande do Sul e Santa Catarina, necessitaram ser abertos para que os limites de armazenamento desses reservatórios não fossem atingidos. Com o excepcional aumento no volume desses reservatórios, e respectiva abertura de seus vertedouros, pontes e viadutos da região tiveram sua estrutura física comprometida, deixando, inclusive, muitas pontes submersas.

Houve, também, o caso do rompimento de uma barragem particular $(\mathrm{PCH})$ localizada no município de Ponte Serrada (SC), próximo ao município de Arvoredo, no oeste catarinense, a qual demandou a rápida evacuação de sua população das áreas mais baixas da cidade.

As consequências sociais, econômicas e ambientais, bem como os danos causados pelas chuvas excessivas, não foram restritas apenas as regiões do alto Uruguai gaúcho e oeste catarinense. Nos dias subsequentes, o elevado volume do rio Uruguai promoveu transtornos ao longo de toda sua calha, na divisa entre o Rio Grande do Sul e território argentino.

Cidades como São Borja, Itaqui e Uruguaiana, localizadas no médio e baixo curso da bacia, sofreram, por dias, os efeitos das cheias do rio Uruguai, multiplicando o número de desabrigados e de problemas estruturais em decorrência das chuvas. 
A partir da ocorrência de eventos de intensa precipitação, como neste caso, surgem novos (antigos) questionamentos: é comum ocorrerem eventos dessa natureza, sobretudo, nessa época do ano? Essa sequência de dias de chuva estaria associada à participação de fenômenos de variabilidade conhecida como o El Niño Oscilação Sul (ENOS)? Não seriam esses eventos evidências das mudanças climáticas?

Visando responder a esses e outros questionamentos, é que o presente trabalho se objetiva identificar a ocorrência de eventos acumulados de intensa precipitação em parte da região do alto Uruguai gaúcho, bem como, também, identificar os mecanismos responsáveis pela sua ocorrência.

\section{METODOLOGIA}

Para o desenvolvimento do trabalho foram utilizados dados pluviométricos diários obtidos da rede de postos da Agência Nacional de Águas (ANA), através da plataforma hidroweb (http://hidroweb.ana.gov.br), da Fundação Estadual de Pesquisa Agropecuária (FEPAGRO) e do Instituto Nacional de Meteorologia (INMET). Foram selecionadas informações dos postos pluviométricos de Quatro Irmãos (RS), com dados no período de 1961 a 1981 (20 anos), Erebango (RS), com dados no período de 1982 a 2002 (20 anos) e de Erechim (RS), com dados no período de 2003 a 2014 (11 anos).

No tratamento inicial dos dados, verificou-se a existência de falhas (ausência de dados) nos conjuntos selecionados, as quais se devem, provavelmente, à ausência de um observador no período.

Caldeira et al. (2011) afirmam que é habitual deparar-se com séries que possuem ausência de dados, podendo levar a análises errôneas e tendenciosas, comprometendo os resultados. Para isso necessita-se a adoção de procedimentos estatísticos para seus preenchimentos e caracterização ambiental dos sítios escolhidos.

Para a escolha dos postos pluviométricos foram analisadas e consideradas certas características:

1- Distância linear entre os postos menor que $30 \mathrm{~km}$;

2- Semelhança nas características do relevo, da vegetação e do clima;

3- Ausência de falhas no mesmo período.

Os dados utilizados foram obtidos a partir de postos pluviométricos em três municípios: Erebango, Erechim e Quatro Irmãos (Tabela 1).

Tabela 1: Postos pluviométricos utilizados no período analisado

\begin{tabular}{llcc}
\hline Posto & Município & Período Início & Período Término \\
\hline ANA & Quatro Irmãos & 1961 & 1981 \\
ANA & Erebango & 1982 & 2002 \\
FEPAGRO & Erechim & 2003 & 2009 \\
INMET & Erechim & 2010 & 2014 \\
\hline
\end{tabular}

Fonte: Agência Nacional de Águas (ANA). 

trabalho.

A Figura 1 demonstra a localização dos postos pluviométricos utilizados no

Inicialmente, os dados diários de todas as séries foram organizados utilizando

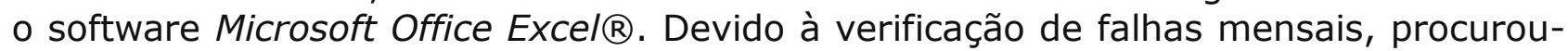
se preenchê-las por meio de técnicas de regressão linear simples entre os postos. Esse método tem sido utilizado, com sucesso, por vários autores, como Alexander (2009), Nascimento et al. (2010), Oliveira (2003), Chechi e Sanches (2013) e Balen e Sanches (2014) entre outros. Para a equação de regressão, utilizou-se como variável de regressão os totais mensais de precipitação de Quatro Irmãos (RS) no período de janeiro de 1958 a dezembro de 1970. Inicialmente foram calculados a equação de regressão (do tipo $y=a x-\beta$ ) e os índices de determinação $\left(R^{2}\right)$ e de correlação $(R)$.

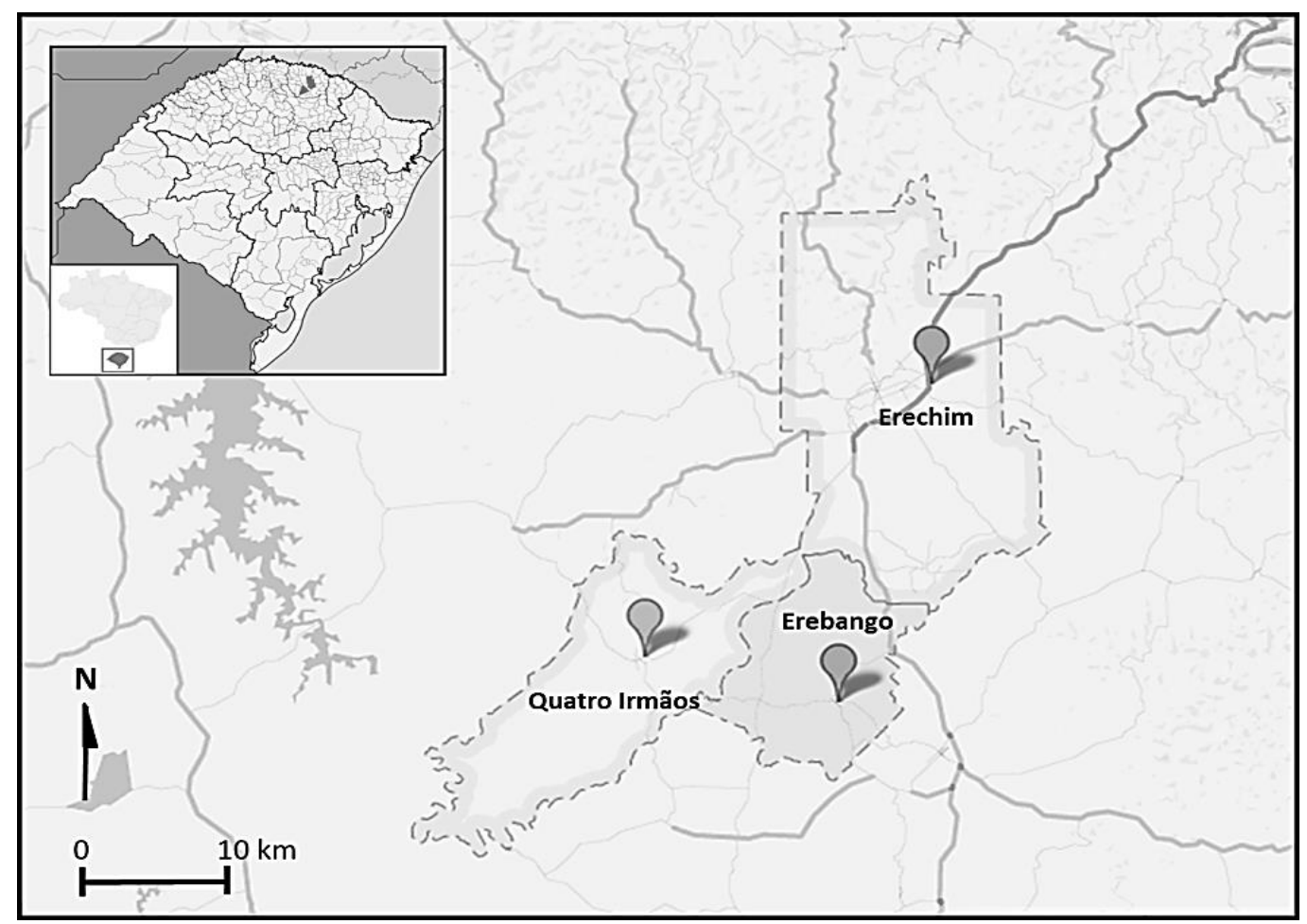

Figura 1: Localização dos municípios de Erechim, Erebango e Quatro Irmãos.

Fonte: Adaptado de https://maps.google.com.br.

Após o preenchimento dos dados, verificou-se a qualidade dos dados por meio de Testes de Correlação Linear para os períodos concomitantes entre os postos e, sua consistência verificada por meio da aplicação do Teste de Dupla Massa. Sugerido por Tucci (2009), o teste de Dupla Massa possui simplicidade e eficácia, pois consiste na comparação de duas curvas que são traçadas no plano cartesiano, uma de totais anuais ou mensais acumulados do posto que a ser analisado e outra da média acumulada dos totais anuais ou mensais de postos confiáveis da região considerada. $A$ aplicação desse método permitiu verificar se os totais acumulados apresentaram proporcionalidade; assim, as informações no gráfico plotado deveriam apresentar-se sobre uma linha reta. Dessa maneira, o Teste de Dupla Massa foi utilizado plotando-se o acumulado dos totais anuais de precipitação da série com o acumulado das médias anuais de precipitação no período.

Assim, após o tratamento estatístico preliminar, obteve-se uma série temporal de dados pluviométricos diários, para a região de Erechim (RS), de 1961 a 2014. 
A busca por episódios acumulados de chuvas intensas levou a aplicação da técnica das pêntadas para todos os 53 anos da série. Uma pêntada constitui o acumulado das precipitações de cinco dias consecutivos, levando ao conjunto anual de 73 pêntadas. Durante os anos bissextos, a $12^{a}$ pêntada foi considerada como 0 somatório de seis dias, ao invés de cinco.

Para definir os valores intensos das pêntadas adotou-se valores com base no percentil 99 da série. Nesse caso, foram considerados valores intensos de pêntadas, aqueles com acumulados superiores a 157,4 mm. A partir desse valor, foi possível extrair a quantidade de eventos intensos (frequência absoluta), o período de ocorrência, a frequência relativa e o tempo de retorno (recorrência) de tais eventos, no decorrer da série.

Por fim, com base nas informações dos valores intensos das pêntadas (número das pêntadas), foi possível reconstruir as condições sinóticas que levaram a formação de tais eventos e, assim, compreender o processo envolvendo sua gênese. Para isso, foram utilizadas cartas sinóticas produzidas pelo Serviço Meteorológico da Marinha do Brasil, disponíveis em seu

(http://www.mar.mil.br/dhn/chm/meteo/prev/cartas/cartas.htm).

\section{RESULTADOS E DISCUSSÕES}

O tratamento inicial se deu a partir da aplicação de testes de correlação linear entre os postos de Erechim e Quatro Irmãos para períodos correspondentes. Observou-se que os dados de ambos os postos possuem elevado índice de correlação, com coeficiente de determinação $\mathrm{R}^{2}=0,98$ (Figura 2). Dessa forma, pode-se inferir a ideia de que os dados de ambos os postos são, estatisticamente, homogêneos e, assim, compor uma série, substituindo as falhas encontradas em um posto pelos valores correspondentes a outro posto.

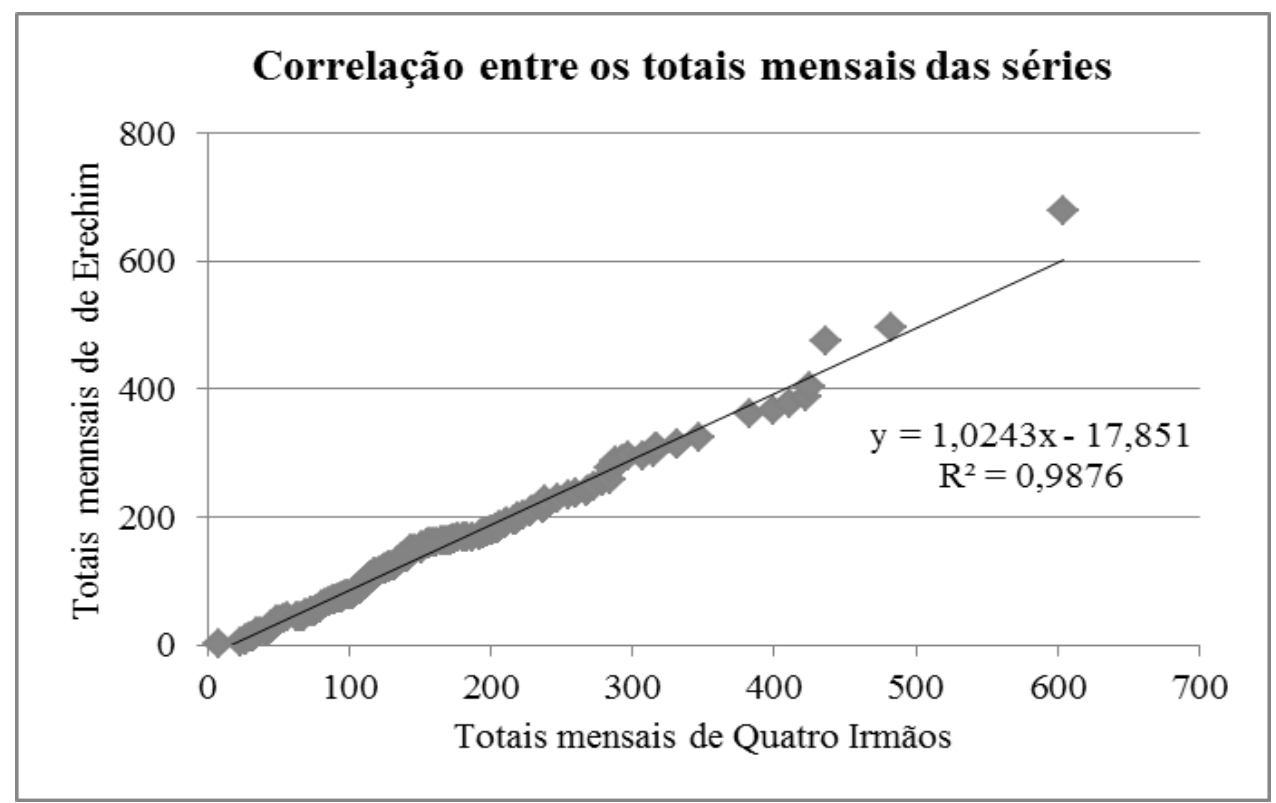

Figura 2: Correlação entre os postos de Erechim e Quatro Irmãos.

Para avaliar a consistência dos dados aplicou-se o teste da Dupla Massa entre os dados dos postos de Erechim e Quatro Irmãos. Verificou-se que os valores obtidos 
para acumulado dos totais anuais de precipitação da série com o acumulado das médias anuais de precipitação no período ficaram sobre uma linha reta (Figura 3), demonstrando alta consistência (99,9\%).

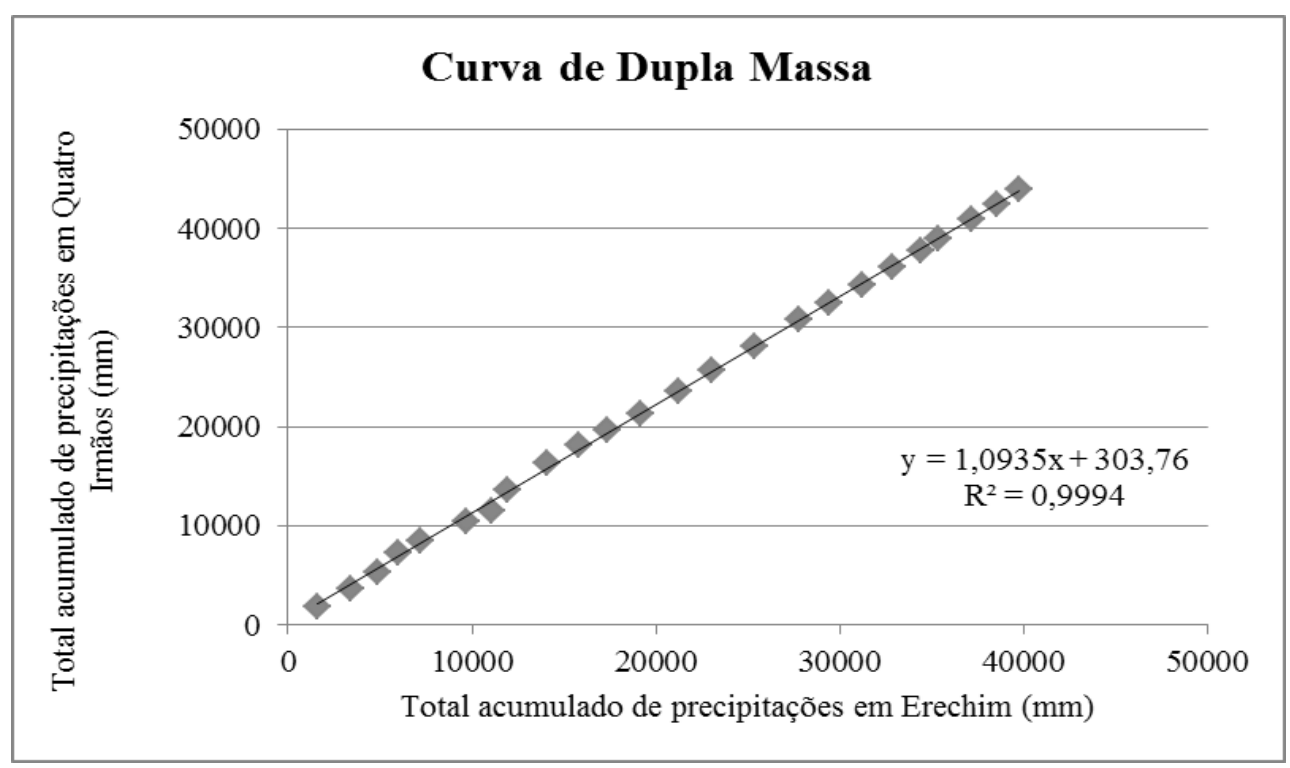

Figura 3: Teste de Dupla Massa entre os dados dos postos de Erechim e Quatro Irmãos.

Dessa forma, de posse de uma série de 53 anos (1961-2014) com dados diários foi possível agrupá-los em sequência anuais de 73 pêntadas a fim de se identificar os valores acumulados intensos, superiores a 157,4 mm (Figura 4). 


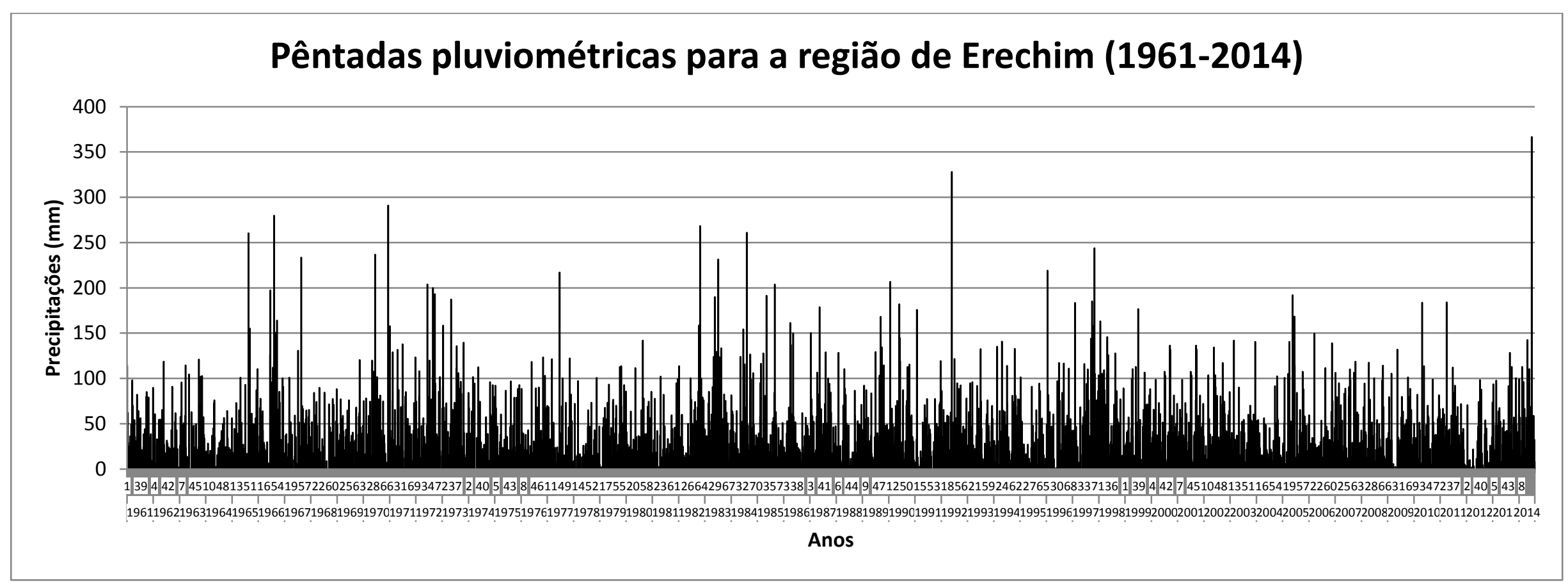

Figura 4. Sequência das pêntadas pluviométricas para a região de Erechim (1961-2014). 
A Figura 4 permite identificar, no decorrer da série analisada, a ocorrência de 40 eventos (pêntadas) considerados de valorintenso.

Inicialmente, a partir dessas informações, foi possível extrair a frequência absoluta dosacumulados intensos, da frequência relativa e do tempo de retorno dos eventos categorizados (Tabela 2).

Tabela 2. Frequência Absoluta, Frequência Relativa e Tempo de Retorno dos eventos acumulados intensos.

\begin{tabular}{lccc}
\hline Categorias & $\begin{array}{c}\text { Freq. } \\
\text { Absoluta }\end{array}$ & $\begin{array}{c}\text { Freq. Relativa } \\
\text { (\%) }\end{array}$ & $\begin{array}{c}\text { Tempo de retorno } \\
\text { (anos) }\end{array}$ \\
\hline Chuvas $>157,4 \mathrm{~mm}$ & 40 & 0,0101 & 1,3 \\
entre 157,4 e $200 \mathrm{~mm}$ & 23 & 0,0058 & 2,3 \\
entre 200 e $250 \mathrm{~mm}$ & 10 & 0,0025 & 5,4 \\
entre 250 e $300 \mathrm{~mm}$ & 5 & 0,0013 & 10,8 \\
entre 300 e $350 \mathrm{~mm}$ & 1 & 0,0003 & 53 \\
entre 350 e $400 \mathrm{~mm}$ & 1 & 0,0003 & 53 \\
\hline
\end{tabular}

Observa-se na Tabela 2 que, desde 1961, os acumulados intensos de chuva ocorrem com muita frequência. Entretanto, merecem destaque os eventos mais intensos já registrados.

Em toda a série analisada foram verificados sete eventos pluviométricos com valores superiores a $250 \mathrm{~mm}$ e, desses sete eventos, os dois mais intensos com acumulados superiores a $300 \mathrm{~mm}$.

Esses acumulados intensos poderiam estar de alguma forma, associados à participação de fenômenos de variabilidade interdecenal como, por exemplo, relacionados à componente positiva fenômeno El Niño Oscilação Sul (ENOS).

Entretanto, ao se analisarem os dez valores mais intensos registrados, e suas respectivas pêntadas, observa-se que $70 \%$ dos casos ocorreram entre as pêntadas 30 e 47 (Tabela 3) entre o início de maio e o final de agosto, ou seja, fora do período de atividade do fenômeno.

Tabela 3. Relação dos dez maiores eventos intensos (pêntadas) na região de Erechim.

\begin{tabular}{cccc}
\hline Ano & Pêntada & Período & Acumulados (mm) \\
\hline 2014 & 36 & $25 / 06$ a $29 / 06$ & 366,7 \\
1992 & 30 & $26 / 05$ a $31 / 05$ & 328,0 \\
1970 & 69 & $07 / 12$ a $11 / 12$ & 290,8 \\
1966 & 44 & $04 / 08$ a $08 / 08$ & 279,6 \\
1982 & 60 & $23 / 10$ a $27 / 10$ & 268,2 \\
1984 & 44 & $04 / 08$ a $08 / 08$ & 261,0 \\
1965 & 46 & $14 / 08$ a $18 / 08$ & 260,3 \\
1997 & 61 & $28 / 10$ a $01 / 11$ & 243,8 \\
1967 & 47 & $19 / 08$ a $23 / 08$ & 233,4 \\
1970 & 33 & $10 / 06$ a $14 / 06$ & 233,4 \\
\hline
\end{tabular}

Sendo assim, a compreensão dos mecanismos geradores desses acumulados extremos só é possível através da interpretação e análise de sua dinâmica sinótica. 


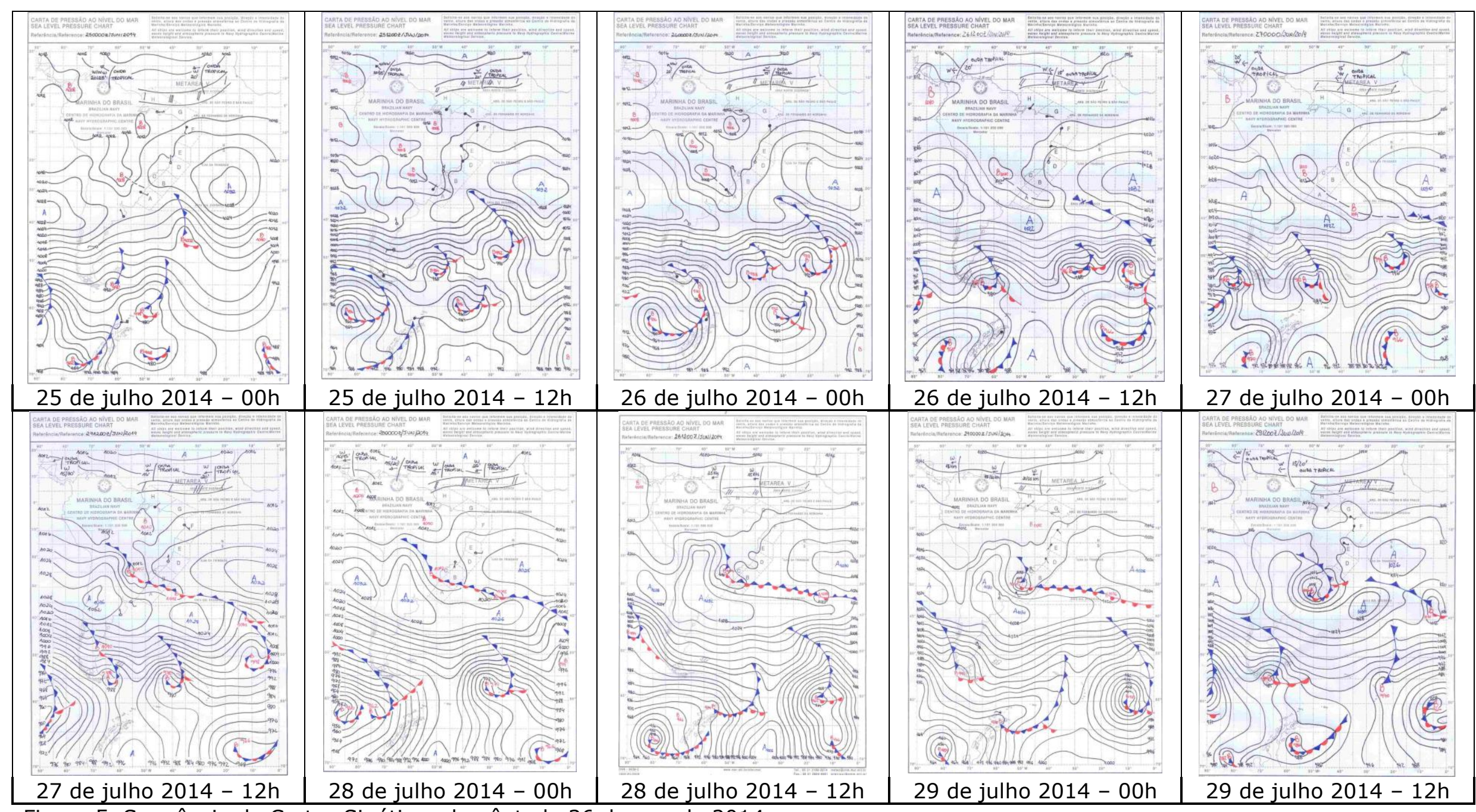

Figura 5. Sequência de Cartas Sinóticas da pêntada 36 do ano de 2014. 
A análise sinótica da pêntada 36 do ano de 2014 (Figura 5) demonstra que, às 12 horas (UTC) do dia 25/06/14, atuava, sobre a região de estudo, um sistema frontal que se estendia do litoral gaúcho e conectava-se a áreas de baixa pressão, provavelmente com formação de cavados, sobre o estado do Rio Grande do Sul e Paraguai, provocando instabilidades.

Embora não se caracterize na sequência das cartas sinóticas, a conecção desses sistemas, tenha se transformado em uma frente estacionária, ondulando pelo sul do Paraguai, norte da Argentina e interior do Rio Grande do Sul. Sua caracterização se confirma na carta das 12 horas (UTC) do dia 27/06/14 estendendo-se, de $12 \mathrm{~h}$ em $12 \mathrm{~h}$, até a00 hora (UTC) do dia 29/06/14, quando se verifica a formação de um ciclone extratropical.

Esse ciclone extratropical, centrado sobre o estado do Rio Grande do Sul, evolui até o final da pêntada sendo, igualmente, responsável pelos elevados valores pluviométricos. Dessa forma, a sequência sinótica descrita na Figura 5 demonstra que as condições favoráveis às precipitações permaneceram constantes no decorrer das 120 horas da pêntada.

No intuito de buscar similaridades sinóticas entre os acumulados intensos observados na série analisada, procedeu-se, igualmente, análises dos eventos com valores pluviométricos em ordem decrescente.

O segundo evento acumulado intenso de maior intensidade registrado na série ocorreu na pêntada 30 do ano de 1992 e sua dinâmica pode ser observada por meio da sequência de cartas sinóticas na Figura 6.

A pêntada30 inicia-se com a carta das 12 horas (UTC) do dia 26 de maio de 1992. Nessa carta, verifica-se a caracterização de um ramo quente de um sistema frontal ondulando pelo centro da América do Sul, conectando-se a um ramo frio do sistema frontal, do estuário do Prata ao litoral argentino.

No dia seguinte (27/05/92 - 12h UTC) observa-se que a junção desses sistemas (Frente quente continental acoplado a frente fria) situa-se entre o sul do Paraguai, oeste catarinense, norte do Rio Grande do Sul, seguindo pelo litoral gaúcho e, desenvolvendo uma linha de instabilidade de baixa pressão de noroeste a sudeste.

A partir da carta das 12 horas (UTC) do dia 29 de maio de 1992 verifica-se que o sistema segue rumo ao norte do Paraná mantendo a linha de instabilidade sobre o Atlântico, culminando, ao final da pêntada (30/05/1992) num sistema de estacionário, constituindo em um canal de umidade do noroeste do estado de São Paulo até o seu litoral. Assim, a sequência sinótica permite verificar que esse sistema permaneceu, ao menos 32 horas, promovendo precipitações sobre a região de estudo.

$\mathrm{Na}$ mesma Figura 6 observa-se a sequência sinótica do acumulado intenso da pêntada 44 no ano de 1966, atingindo valores pluviométricos $219,6 \mathrm{~mm}$.

A carta das $12 \mathrm{~h}$ (UTC) do dia 4 de agosto de 1966 mostra um sistema frontal frio atuando sobre a região de estudo. Somente nesse dia, as condições de tempo instável, com chuvas e trovoadas, registraram um total de $168,5 \mathrm{~mm}$. 
Na carta do dia 5 de agosto de 1966 (12 h - UTC) verifica-se que, embora a frente fria tenha se deslocado para nordeste, as condições atmosféricas ainda promoveram precipitações na região de estudo. A sequência de cartas sinóticas da pêntada 44 demonstrou que a alta pressão está centrada, justamente, sobre a região de estudo, estabilizando as condições de céu claro.

Verifica-se, dessa forma, que o acumulado intenso registrado na pêntada 44 do ano de 1966 não possui as mesmas condições sinóticas de formação dos anos de 2014 e 1992. 


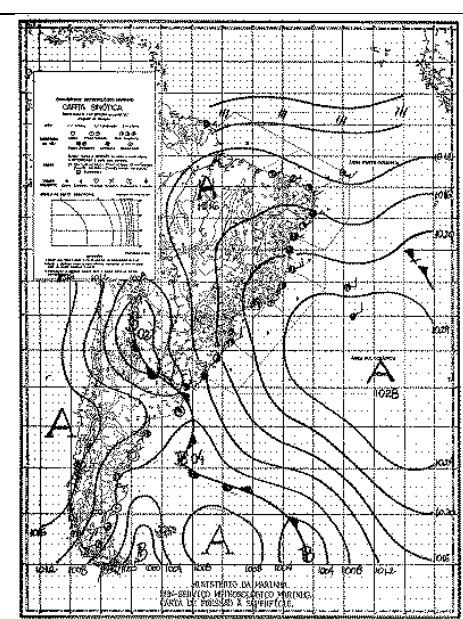

26 de maio $1992-12 \mathrm{~h}$

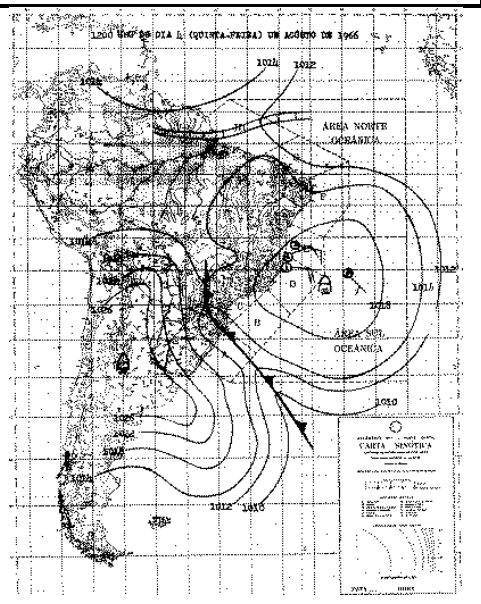

04 de agosto $1966-12 \mathrm{~h}$

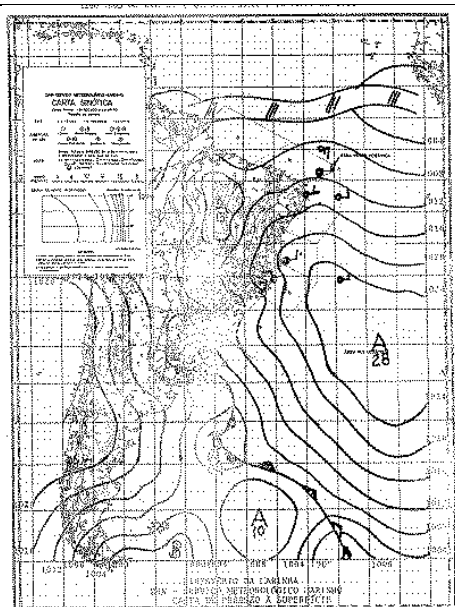

27 de maio $1992-12 \mathrm{~h}$
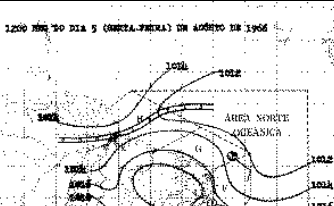$$
\text { - }
$$

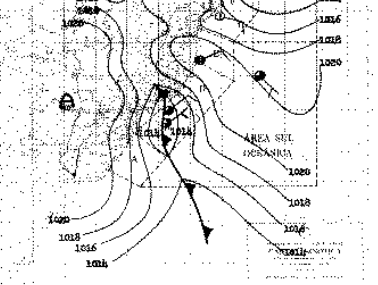

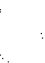

05 de agosto $1966-12 \mathrm{~h}$

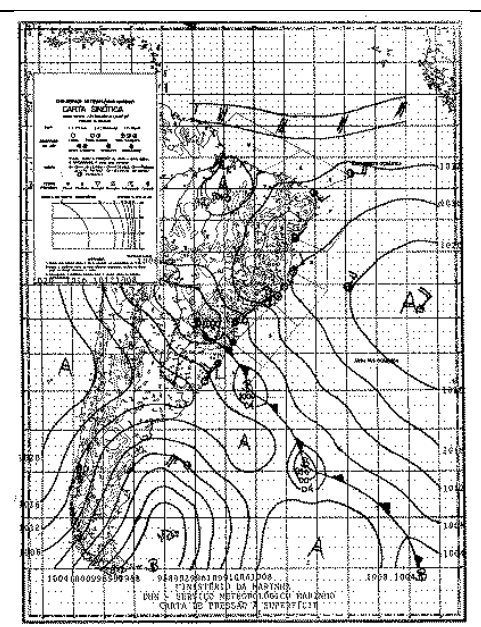

28 de maio $1992-12 \mathrm{~h}$
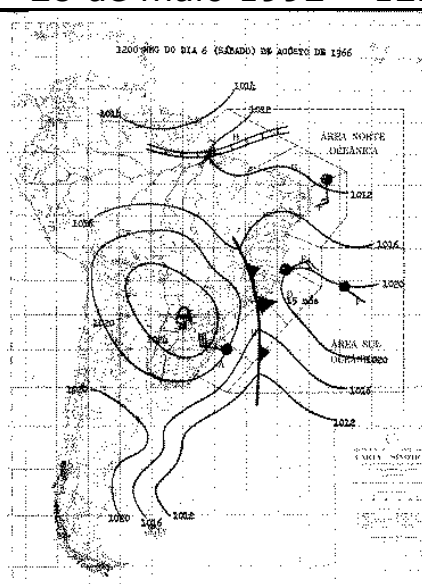

06 de agosto $1966-12 \mathrm{~h}$

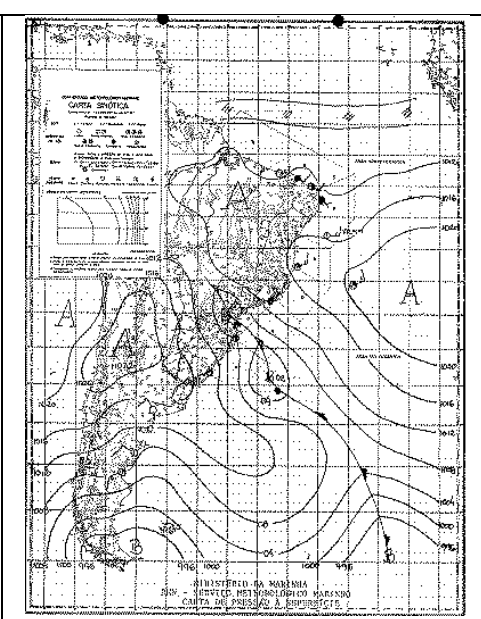

29 de maio $1992-12 \mathrm{~h}$
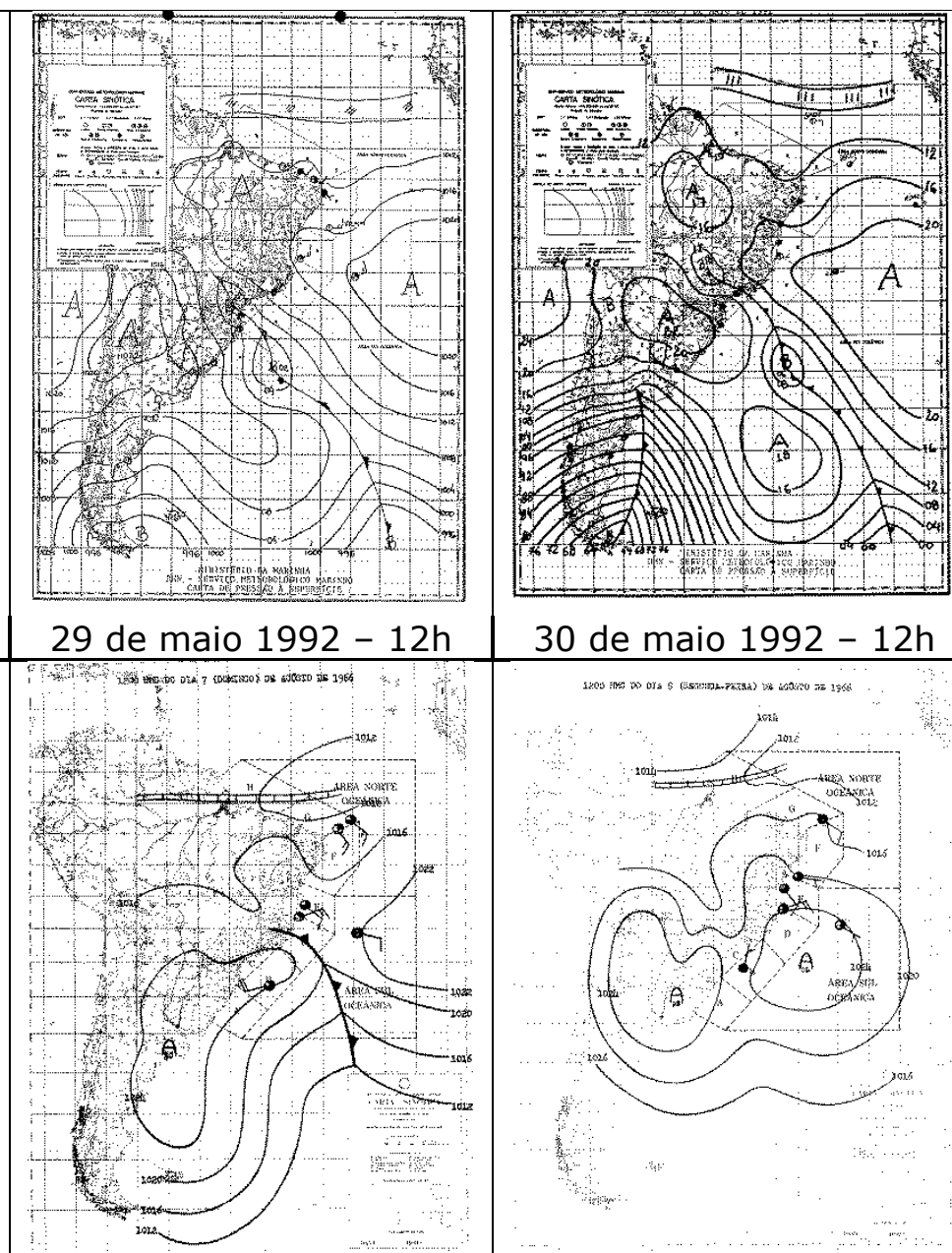

30 de maio $1992-12 \mathrm{~h}$

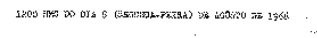

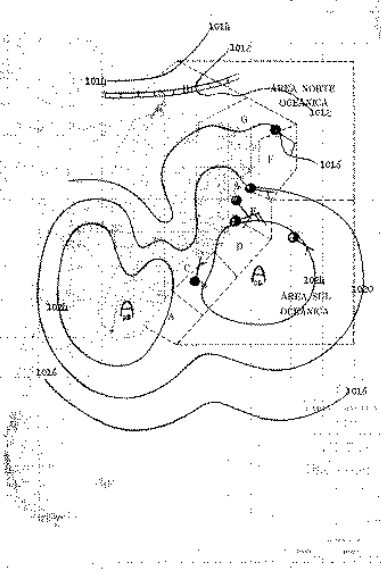

Figura 6. Sequência de Cartas Sinóticas da pêntada 30 do ano de 1992 (superior) e da pêntada 44 do ano de 1966 (inferior). 
Uma das características que marcam os eventos acumulados de 2014 e 1992 é a conecção de sistemas frontais quentes aos sistemas frontais frios formando, no decorrer das horas, um sistema frontal estacionário.

Carvalho e Fedorova (2011) destacam em seu trabalho que, ao contrário das frentes frias, as frentes quentes têm recebido pouca atenção por parte de pesquisadores, provavelmente devido a sua baixa frequência de atuação e limitada extensão horizontal. Para as autoras, as frentes quentes ocorrem nos meses de outono, inverno e primavera, ondulando sobre a região sul do Brasil, principalmente sobre o Rio Grande do Sul.

A sequência de cartas sinóticas do acumulado intenso da pêntada 44 de 1984 (Figura 7) traz, novamente, as condições atmosféricas semelhantes às observadas nos acumulados intensos dos anos de 2014 e 1992.

A carta das 12 horas (UTC) do dia 4 de agosto de 1992 indica um centro de baixa pressão localizado no norte da Argentina e um sistema frontal frio atuando no litoral argentino. Dados os valores barométricos existentes entre o centro da baixa pressão (1004 hPa) e a frente fria no litoral argentino (996 hPa) nota-se uma condição potencial para a conexão desses dois sistemas, sobretudo, analisando a carta das 12 horas (UTC) do dia 5 de agosto de 1984.

Novamente, embora não seja apontada na carta, a possibilidade de formação de um cavado atmosférico, que, no decorrer dos dias subsequentes, se acoplaria ao ramo frio do sistema frontal, formou um alinhamento estacionário (carta das $12 \mathrm{~h}$ - UTC - do dia 06/08/84). Dessa forma, observa-se um clássico alinhamento no sentido noroeste-sudeste até o Atlântico sul.

Esse alinhamento de sistemas foi responsável pelos $87,8 \mathrm{~mm}$ e 122,8 $\mathrm{mm}$ nos dias 6 e 7 de agosto demonstrando que, essa frente estacionária, permaneceu sobre a área de estudo por, pelo menos, 36 horas.

Na carta das 12 horas (UTC) do dia 08 de agosto de 1992 a frente estacionária já ondulava sobre sudeste do país promovendo precipitações entre os estados de Minas Gerais e litoral fluminense.

O conjunto sinótico da pêntada 46 do ano de 1965 traz a dinâmica de dois sistemas frontais sobre a área de estudo no decorrer dos cinco dias. $\mathrm{Na}$ carta das 12 horas (UTC) do dia 14 de agosto de 1965 verifica-se a atuação de um alinhamento de baixa pressão estendendo-se do Paraguai, passando por Santa Catarina e norte-nordeste gaúcho. Os valores pluviométricos para esse dia atingiram $18 \mathrm{~mm}$. Na carta sinótica do dia seguinte (12h - UTC de 15/08/2014) a indicação da linha da frente fria, sugere um rápido deslocamento para nordeste, atuando sobre o estado de São Paulo e seu litoral.

No entanto, a carta das $12 \mathrm{~h}$ (UTC) do dia 16 de agosto mostra uma nova frente fria avançando, rapidamente, sobre o estado do Rio Grande do Sul trazendo, nas cartas dos dias 17 e 18 de agosto, a permanência desse novo sistema frontal sobre o estado de Santa Catarina e norte do Rio Grande do Sul. Nesses dois dias (48 horas), os valores pluviométricos registrados foram de $117,3 \mathrm{~mm}$ e $125 \mathrm{~mm}$, respectivamente. 
Condições sinóticas similares são, igualmente, descritas nos trabalho de Fedorova e Carvalho (2000). Para as autoras, esse rápido deslocamento de uma frente fria pode promover a formação de uma nova frente fria (secundária) onde, na estrutura dessa frente secundária, são comuns as condições de pancadas de chuva com elevados valores, bem como a formação de ciclones e cavados báricos após a oclusão do ciclone. 


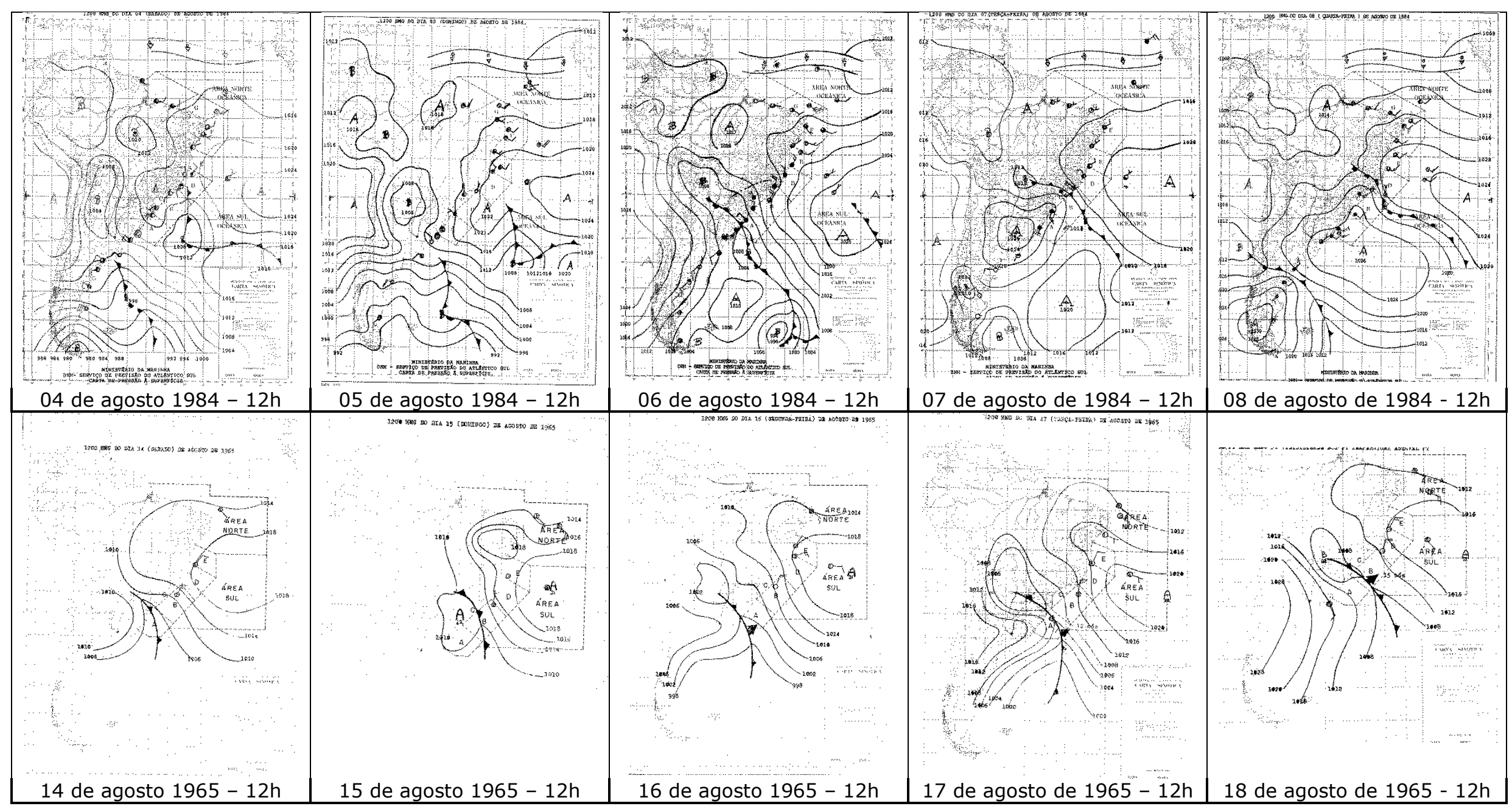

Figura 7. Sequência de Cartas Sinóticas da pêntada 44 do ano de 1984 (superior) e da pêntada 46 do ano de 1965 (inferior). 
Já as cartas sinóticas que descrevem a dinâmica atmosférica durante a pêntada 47 de 1967 (Figura 8) trazem, novamente, condições muito semelhantes às encontradas nas pêntadas analisadas nos anos de 2014, 1992 e 1984, demonstrando a formação clássica de uma frente estacionária.

A carta das 12 horas (UTC) do dia 19 de agosto de 1967 indica a formação de uma frente fria no litoral norte gaúcho (município de Tramandaí) trazendo instabilidade para o centro do estado, uma vez que, a baixa pressão está centrada no interior do Paraguai. Na carta das $12 \mathrm{~h}$ (UTC) do dia 20 de agosto de 1967 configura-se a formação de uma frente fria estendendo-se ao sul do Paraguai e por todo o estado do Rio Grande do Sul com movimento típico na direção nordeste.

No dia 21 de agosto de 1967, o alinhamento do ramo frio muda sua posição de NO/SE para ESE graças ao centro de alta pressão do Anticiclone Migratório Polar (em 1040 hPa) estar localizado no litoral da Patagônia. Tal condição sinótica favorece a formação de áreas de baixa pressão do centro da América do Sul, as quais avançam sobre o estado do Rio Grande do Sul conectando o ramo de uma frente quente com a linha da frente fria, estacionando o sistema.

Já, no dia 23 de agosto de 1967 (12h - UTC) o centro do Anticiclone Migratório avança sobre a região do estuário do Prata deslocando o alinhamento da frente estacionária para nordeste, posicionando-a sobre o interior de São Paulo e litoral paranaense.

Por fim, a sequência sinótica da pêntada 33 de 1970 (Figura 8) demonstra a dinâmica de outra frente estacionária localizada sobre região de estudo, entre os dias 11 e 14 de junho. Na carta das 12 h (UTC) do dia 11 de junho de 1970 observa-se a formação de um sistema frontal frio que avança pelo estado do Rio Grande do Sul. No dia seguinte (12/06/1970) o sistema frontal estaciona-se sobre nordeste e norte gaúcho em função do centro de baixa pressão localizar-se sobre o Paraguai conectando, provavelmente por meio de cavados, a uma frente com características quentes no dia 13 de julho de 1970.

A convergência de ventos quentes e úmidos de NO conectam-se a linha de instabilidade do ramo frio formando um canal de umidade desde o sul do Mato Grosso do Sul, passando pelo oeste do Paraná, Santa Catarina e pelo norte e nordeste do Rio Grande do Sul em direção ao Atlântico. No dia seguinte (14/06/70) a alta pressão sobre o centro-norte argentino favorece a propagação do sistema frontal, ora estacionário, para o norte do Paraná e sul de São Paulo.

Sendo assim, a análise sinótica demonstra que os principais eventos acumulados intensos possuem condições atmosféricas similares. Sua principal característica é a convecção de sistemas frontais quentes com sistemas frontais frios estacionando-se sobre o local de estudo por, no mínimo, 36 horas. 


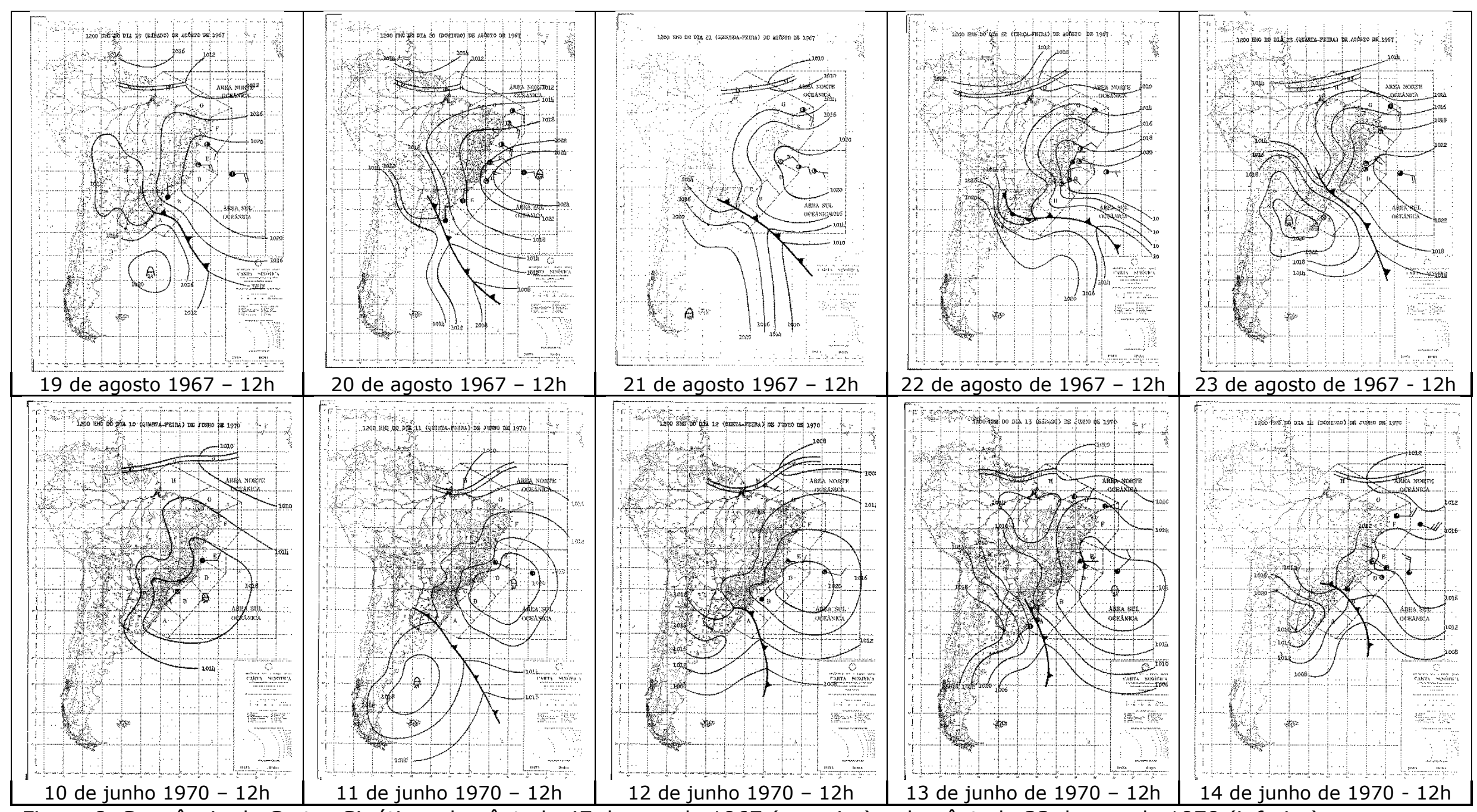

Figura 8. Sequência de Cartas Sinóticas da pêntada 47 do ano de 1967 (superior) e da pêntada 33 do ano de 1970 (inferior). 


\section{CONSIDERAÇÕES FINAIS}

A reconstrução da série temporal de 53 anos de dados pluviométricos diários para a região do Alto Uruguai gaúcho (Erechim e entorno) permitiu que fossem identificados os acumulados de cinco dias (pêntada) mais intensos do período.

Foi possível observar que eventos intensos de precipitação ocorreram em, praticamente, todos os anos da série. No entanto, acumulados de maior intensidade (superiores a $300 \mathrm{~mm}$ ) ocorreram, apenas duas vezes no período.

De acordo com os dados observados, os eventos dos anos de 2014 e 1992 foram os mais intensos, acumulando, respectivamente, $366,7 \mathrm{~mm}$ e $328,0 \mathrm{~mm}$ sendo o tempo de retorno desses eventos, de acordo com as estatísticas, de 54 anos.

A análise sinótica desses dois eventos demonstrou profunda semelhança uma vez que ocorreram em consequência da estacionaridade de um sistema frontal acoplando um ramo frontal quente a um ramo frontal frio. A diferença entre ambas foi, apenas, o tempo de permanência do escoamento frontal sobre o local de estudo. O evento de 2014 foi de 120 horas e o de 1992, 32 horas.

Já os casos de acumulados intensos entre 200 e 250 mm, o tempo de retorno foi de cinco anos. A condição sinótica também foi semelhante sendo menor o tempo de permanência desses sistemas sobre o local de estudo.

O fato da maior parte desses eventos ter ocorrido entre as pêntadas de número 30 e 47 (inicio de maio ao final de agosto) demonstra que a componente positiva do fenômeno ENOS, muito provavelmente, não tenha exercido influência direta na ocorrência dos mesmos.

A dinâmica observada nos casos analisados reforça as ideias Silva Dias (2006) de que a ocorrência eventos extremos como chuvas fortes, ventos fortes ou furacões, estaria associada às mudanças climáticas. Marengo e Valverde (2007) compartilham dessas ideias afirmando que esses eventos extremos têm afetado diretamente partes do planeta e produzido enormes perdas econômicas e de vidas.

O 50 Relatório do IPCC (AR5) reforça as afirmações de que, com o aumento da temperatura média da superfície global, os eventos extremos de precipitação sobre os continentes em latitudes médias e regiões tropicais, como visto no decorrer do presente trabalho, muito provavelmente, se tornarão mais intensos e frequentes até o final do século XXI (IPCC, 2013).

Como os períodos de outono, de inverno e primavera são os que, preferencialmente, ocorrem avanços de frentes quentes sobre o Sul do Brasil (CARVALHO e FEDOROVA, 2011), a intensificação desses sistemas, nos últimos anos, acoplando-se com sistemas frontais frios e modulando por um maior período de tempo, pode ser considerada como uma evidência de modificações que estejam ocorrendo na climatologia do fenômeno. 
Marengo et al. (2007) afirmam que tendências positivas na chuva máxima acumulada em 5 dias têm sido observadas nas latitudes mais austrais que $20^{\circ} \mathrm{S}$ na América do Sul durante a primavera, verão e outono. No entanto, no caso em tese, a intensificação desse eventos acumulados têm ocorrido entre o outono e o inverno, sugerindo que o avanço dos sistemas frontais quentes sobre os sistemas frios, gerando sistemas estacionários, sejam os responsáveis pelo aumento dos acumulados intensos.

Por fim, Borsato e Souza Filho (2010) verificaram que, a partir da década de 1990, a participação das chuvas convectivas tem aumentado significativamente devido ao aumento da participação dos sistemas de baixas pressões no interior do Brasil decorrentes de um maior aquecimento basal.

Sendo assim, com base nas análises estatística e sinótica, é possível concluir que a ocorrência de tais eventos no período de outono/inverno não devemser considerados como eventos "normais", pois, além de fugirem à climatologia das chuvas, têm se tornado cada vez mais intenso nos últimos anos, trazendo transtornos de ordem socioeconômica e estrutural à sociedade.

\section{REFERÊNCIAS}

ALEXANDER, L.V, et. al. Global observed changes in daily climate extremes of temperature and precipitation. Journal of Geophysical Research, v. 111, D05109, 2006.

BALEN, D.S.; SANCHES, F.O. Tendência das chuvas diárias no Alto Uruguai gaúcho entre 1957-2013. In: ROSA, K.K.; SPINELLI, J. (Org) Geografias da "Fronteira Sul": construindo e compartilhando experiências. NETAP/UFFS, 2014. (no prelo)

BORSATO, V.A.; SOUZA FILHO, E.E. A participação dos sistemasatmosféricos atuantesna bacia do rio Paraná no período 1980 a 2003. Revista Brasileira de Climatologia. $\quad$ v.7, n.6, 2010.2 Disponível em <http://ojs.c3sl.ufpr.br/ojs2/index.php/revistaabclima/article/view/25636/17173> acesso em 18 de maio de 2013.

CALDEIRA, T.L; ARAÚJO, M.M.F.; BESKOW, S. Análise de série hidrológica de precipitação no sul do Rio Grande do Sul para aplicação na gestão e monitoramento de recursos hídricos. In: IV Encontro Sul-brasileiro de Meteorologia. Anais, Pelotas, 2011.

CARVALHO, M.H.; FEDOROVA, N. Estudo sobre frentes quentes que ocorrem no Sul do Brasil. Revista Brasileira de Meteorologia, v.26, n.2, 257-272, 2011.

CHECHI, L.; SANCHES, F.O. O uso do Índice de Anomalia de Chuva (IAC) na avaliação do fenômeno do El Niño Oscilação Sul (ENOS) no Alto Uruguai Gaúcho entre 1957-2012. Revista Brasileira de Geografia Física, v.06, n.06, 2013.

FEDOROVA, N. CARVALHO, M.H. Processos sinóticos em anos de La Niña e de El Niño parte II: Zonas Frontais. Revista Brasileira de Meteorologia, v.15, n.2, 5772, 2000.

IPCC.Technical Summary. In: Climate Change 2013: The Physical Science Basis. Contribution of Working Group I to the Fifth Assessment Report of the Intergovernmental Panel on Climate Change. Cambridge University Press, Cambridge, United Kingdom and New York, NY, USA, 2013. 
MARENGO, J.A.; ALVES, L.M.; VALVERDE, M.C.; ROCHA, R.P.; LABORDE, R. Eventos extremos em cenários regionalizados de clima no Brasil e América do Syul para o Século XXI: projeções de clima futuro usando três modelos regionais. 2007.Relatório no 1. Mudanças climáticas globais e seus efeitos sobre a diversidade. MMA. CPTEC/INPE, São Paulo: 2007. Disponível em <http://www.grec.iag.usp.br/link_grec_old/outros/ambrizzi/relatorio5.pdf> acesso em 10 de maio de 2011.

MARENGO, J. A.; VALVERDE, M. C. Caracterização do clima no Século XX e Cenários de Mudanças de clima para o Brasil no Século XXI usando os modelos do IPCC-AR4. Revista Multiciência, edição n. 8 - maio, Mudanças Climáticas, Campinas: 2007. Disponível em <http://www.multiciencia.unicamp.br/art01_8.htm> acesso em 12 de maio de 2011.

NASCIMENTO, T. S. et al. Preenchimento de falhas em banco de dados pluviométricos com base em dados do CPC (Climate Prediction Center): estudo de caso do rio Solimões - Amazonas. Revista Brasileira de Climatologia. v. 7, n. 6, 2010. <http://ojs.c3sl.ufpr.br/ojs2/index.php/revistaabclima/article/view/25643/17176> acesso em 04 de março de 2012.

OLIVEIRA, V. P. S. Modelo para geração de séries sintéticas de precipitação. 2003, 156f. Tese de Doutorado (Programa de Pós-Graduação em Engenharia Agrícola). Universidade Federal de Viçosa, Viçosa, 2003.

SILVA DIAS, M. A. F. Efeito estufa e mudanças climáticas regionais. Revista USP, São Paulo, n.71, p.44-51, set./nov., 2006. Disponível em <http://www.revistasusp.sibi.usp.br/scielo.php?pid=S010399892006000400007\&script=sci_arttext $>$ acesso em 12 de maio de 2011.

TUCCI, C. E. M. Hidrologia: ciência e aplicação. 4.ed. Porto Alegre: UFRGS/ABRH, 2009. 